\title{
Prevalence and Risk Factors of Perineal Tears at the Limbe Regional Hospital, Cameroon
}

Prospective Article

\author{
Egbe $\mathrm{TO}^{1 *}$, Kadzem $\mathrm{LN}^{2}$, Takang $\mathrm{WA}^{3}$, Tchounzou $\mathrm{R}^{4}$, Egbe EN ${ }^{5}, \mathrm{Mbu} \mathrm{RE}^{6}$
}

${ }^{1}$ Senior lecturer and Consultant Obstetrician and Gynecologist, Department of Obstetrics and Gynecology, Faculty of Health Sciences, University of Buea, Cameroon.

${ }^{2}$ General Practitioner, District Hospital Mbengwi.

3 Senior lecturer and Obstetrician and Gynecologist, Department of Obstetrics and Gynecology, Faculty of Health Sciences, University of Bamenda, Cameroon.

${ }^{4}$ Consultant Obstetrician and Gynecologist, Gynecology/Obstetrics and Pediatric Hospital Douala, Cameroon.

${ }^{5}$ General Practitioner, District Hospital Poli, Cameroon.

${ }^{6}$ Professor of Obstetrics and Gynecology, Department of Obstetrics and Gynecology, Faculty of Medicine and Biomedical Sciences, University of Yaounde, Cameroon.

\section{Abstract}

Background: Most of the studies on the prevalence and predisposing factors of perineal tears have been in developed countries. A few studies have been carried out in developing countries including Cameroon. The aim of this study is two fold: to 1) determine the prevalence and risk factors of perineal tear during vaginal delivery at the Limbe Regional Hospital, and 2) provide baseline data needed in auditing obstetric practice.

Patients and Methods: This is a retrospective and prospective cross-sectional study. The retrospective data were obtained from the birth registers. Data was obtained for two consecutive years: 2011 and 2012, and included a total of 1336 birth records that were analysed to determine the prevalence and types of perineal tear and prevalence of episiotomies.

The prospective study comprised a total of 200 women who gave birth at the LRH during the period January 21st through May $24^{\text {th }} 2013$. They were administered a structured questionnaire. The data for the prospective study was used to determine the predisposing factors of perineal tear. Data analysis was with Epi Info 7.0, and Microsoft Excel 2010 version. Statistical significance was set at $\mathrm{P}<0.05$.

Results: The average age of the participants was 25.8 (SD 5.0). The prevalence of perineal tear at the LRH was $19.2 \%$ and that of episiotomies was $2.3 \% .13 .1 \%$ of perineal tears were second-degree tears. Factors identified to be independently associated with perianal tears were: maternal age (25-40) (OR 2.6, 95\% CI: 1.1-4.3; $\mathrm{P}=0.02)$, history of previous perineal tear (OR 3.4, 95\% CI: 1.6-7.3;P<0.001), Antenatal care (ANC) visits $(<4)$ (OR 2.4, 95\% CI: 1.26-4.53; P < 0.007), position of presenting part (occiputo-posterior) (OR 3.2, 95\% CI: 1.6-6.12; $\mathrm{P}<0.001)$ and duration of second phase of labour $(>30 \mathrm{~min}-$ utes) (OR 3.2, 95\% CI: 1.7-6.04; $\mathrm{P}<0.001)$.

Conclusion: The prevalence of perineal tear was much higher than those of episiotomies in the LRH. Second-degree tears were more prevalent among the participants. Perineal outcomes at the LRH were excellent and should be maintained or improved.

Keywords: Perineal Tear; Episiotomy; Vaginal Delivery; Limbe Regional Hospital.

\section{Introduction}

Most of the studies that had been conducted on the prevalence and predisposing factors of perineal tears had been done in the developed countries. A total of 214599 women who underwent vaginal delivery were analysed in the study by Hirayama F. et al.,
2012 [1]. The reported prevalence of third and fourth-degree perineal lacerations ranged differently across countries, from $0.1 \%$ (China, Cambodia, India) to $15.0 \%$ (Philippines); and facilities from zero to $76.3 \%$. After removing facilities with no third or fourth-degree perineal lacerations, and those with too high figures, the range in prevalence went from $0.1 \%$ (Uganda) to $1.4 \%$

\footnotetext{
*Corresponding Author:

Thomas Obinchemti Egbe, MD,

Department of Obstetrics and Gynecology, Faculty of Health Sciences, University of Buea, Cameroon.

E-mail: obinchemti@yahoo.com; toegbe@gmail.com; tom.egbe@outlook.com

Received: August 04, 2016

Accepted: August 23, 2016

Published: August 29, 2016

Citation: Egbe TO, Kadzem LN, Takang WA, Tchounzou R, Egbe EN, et al., (2016) Prevalence and Risk Factors of Perineal Tears at the Limbe Regional Hospital, Cameroon. Int J Reprod Fertil Sex Health. 3(3), 70-78. doi: http://dx.doi.org/10.19070/2377-1887-1600013

Copyright: Egbe TO $^{\circ}$ 2016. This is an open-access article distributed under the terms of the Creative Commons Attribution License, which permits unrestricted use, distribution and reproduction in any medium, provided the original author and source are credited.
} 
(Japan). Forceps-assisted delivery, nulliparity and high birth weight were significant risk factors in all the 373 facilities in the study [1]. Vacuum-assisted delivery was also a significant risk factor in Africa and Asia [1].

Perineal and pelvic floor morbidity has been reported to be greatest among women receiving median episiotomy versus those remaining intact or sustaining spontaneous perineal tears. Median episiotomy was causally related to third-and fourth-degree tears [2]. Furthermore, physicians with favourable views of episiotomy were more likely to use techniques to expedite labour, and their patients were also more likely to have perineal trauma and to be less satisfied with the birth experience [2,3]. Determinants of sulcus tears appear to be present before pregnancy; third- and fourth-degree tears are related to physician management. Exercise mitigates the potential for severe trauma induced by episiotomy [4]. Episiotomy use should therefore be restricted to specified fetal-maternal indications [2].

In Cameroon, the incidence of perineal tear was $13.5 \%$ (230/1695). About $22.1 \%$ of the cases were second-degree tears, and $1.3 \%$ third-degree. No fourth-degree tears were observed. Risk factors for second-degree tears were nulliparity, especially where maternal age was 27 and above, fetal weight of $3500 \mathrm{~g}$ or more, and instrumental and adolescent deliveries, while those of third-degree tears were forceps delivery ( 1 case) and macrosomia ( 2 cases) in patients of 27 and 29 years old [5].

Reducing genital trauma and in particular perineal tear during childbirth is a priority for women and their caregivers. This reduction will check maternal morbidity and mortality caused by perineal tear. This objective meets one of the targets of the Sustainable Development Goals (SDG) which aims at improving maternal health and family planning by the year 2015 and $2030[6,7]$.

There is currently insufficient evidence-based data that recommend the routine use of episiotomy. Therefore, clinical judgment is believed to be the best guide for this procedure [8].

Data from Cameroon are from previous reports rather than the present study. The few existing studies report increased rates of episiotomies and perineal tear among adolescent girls in Yaounde [9]. There have been very few studies in the South West Region on perineal tears. The prevalence of this obstetric complication in the Limbe Regional Hospital seems to be higher than what has been described in other settings.

The aim of this study is two fold: to 1) determine the prevalence and risk factors of perineal tear during vaginal delivery at the Limbe Regional Hospital, and 2) provide baseline data needed in auditing obstetric practice.

\section{Patients and Methods}

\section{Study design and setting}

The study used a retrospective descriptive design to determine the prevalence and types of perineal tear during the period January 1, 2011 to December 31, 2012 and a prospective cross-sectional design mainly to identify the predisposing factors of perineal tear during the period January 21 to May 24, 2014. Ethical clearance for the study was obtained from the Institutional Review Board of the University of Buea, authorization from the Regional Delegate of Health for the South West Region, and administrative approval from the Director of the LRH, the Head of the Obstetrics and Gynaecology Unit of the Limbe Regional Hospital (LRH). Participants were enrolled into the study only after signing informed consent forms.

This study was hospital-based and was carried out at the LRH maternity. Situated in Mile One, Limbe, the LRH is part of the Limbe Health District. It is a 200-bed secondary health-care institution that serves as one of the referral hospitals in the South West Region of Cameroon, and caters to a population of about 200000 inhabitants.

The Obstetrics and Gynecology Department of that hospital has a capacity of 19 beds, with two consultant obstetricians and gynecologists, one midwife, one state-registered nurse and three nursing assistants. The infant welfare care (IWC) and antenatal care (ANC) units are separate from the labour ward and the rest of the maternity unit.

\section{Sample Size Calculation and Sampling}

The sample size needed to calculate the prevalence of perineal tear was obtained as follows:

$n=\frac{z^{2} p q}{d^{2}}$

$\mathrm{p}=13.5 \%$ : pre-study estimate of the prevalence of perineal tear at the University Teaching Hospital Yaoundé [5].

$\mathrm{d}=$ degree of precision (accuracy) $=5 \%$

$Z=$ standard normal variate; it depends on the confidence level. In this study the error level $(\alpha)$ was considered at 0.05 and the confidence interval was $95 \%$. This corresponded to a normal standard variate $(\mathrm{Z})$ of 1.96 .

$\mathrm{N}=\frac{(1.96)^{2}(0.135)(0.865)}{(0.05)^{2}}=179.4=179$ participants

A minimum of 179 participants was needed to calculate the prevalence of perineal tear in this study. Retrospective data was also used for the same purpose, thus the 1336 records included were far above the 179 required for the study.

\section{The retrospective phase}

The period January 1, 2011 to December 31, 2012 generated a total of 1339 medical records for analysis. Authorization to access medical records was obtained from the Director of the LRH. Information regarding maternal age, delivery type, maternal HIV status, presence or absence of perineal tear, type of tear, use of episiotomy, fetal birth weight and APGAR scores was obtained from the birth records at the Department of Obstetrics and Gynaecology of the LRH.

Birth records with incomplete information on the items indicated above were excluded from the retrospective study, as were birth 
records of women who delivered out of the LRH.

\section{The prospective phase}

This phase lasted for a period of 4 months, from January 21 to May 24, 2013, and a total of 200 women were enrolled by convenience sampling method for study after signing a written informed consent form. A structured, pre-tested survey questionnaire was administered to women who delivered the night before and to those in labour. The latter were closely followed up to ensure that labour and delivery were well managed by the birth attendant.

The questionnaire was filled by the study participants and their weights and heights measured. Interviews were carried out in English or Pidgin English. Data was collected on certain sociodemographic variables (age, residence, marital status, parity, educational level of participant and partner, monthly income, outcome of previous pregnancies) and outcome variables (number of ANC sessions attended, number of ANC sessions missed, timing of the first ANC visit, and activities done during each visit and recommendations given). The partogram was opened at the active phase of labour when the patient was at $4 \mathrm{~cm}$ dilation and filled appropriately till delivery. After delivery, the duration of labour and occasioned complications especially regarding perineal tears, episiotomies, APGAR scores, birth weight and blood loss were noted.

Women who came for ANC and IWC, those with records of multiple pregnancies, and women who delivered by caesarean section or at home were excluded from the prospective study.

\section{Data Management and Analysis}

Data analysis was done using Epi info version 7.0 (CDC, Atlanta, USA) and Microsoft Excel 2010. Demographic data (age, religion, level of education and marital status, gravidity, parity, HIV status, place and number of ANCs, labour parameters, BMIs, and history of perineal tears and episiotomies) were expressed as frequencies in charts and tables. The prevalence of episiotomies and other perineal tears were obtained retrospectively and expressed as percentages. Perineal tears with possible associated factors were compared in a 2 by 2 table using Chi Square or Fisher's exact tests as appropriate. Univariable analysis of factors associated with perineal tears was done by logistic regression and those factors which had a cut-off $\mathrm{p}$-value of $\leq 0.1$ were included in the final multivariable logistic regression model and results were expressed respectively as odd ratios and adjusted odd ratios with their $95 \%$ confidence interval. Evidence of statistical association was considered significant for a two-tailed $\mathrm{p}$-value $\leq 0.05$.

\section{Results}

This study had a total of 1536 participants. The retrospective phase assembled 1336 records, and the prospective phase 200.

Table 1: The mean age of study participants in the prospective study was 25.8 (SD 5.0), range 16-40. The age groups 26 to 30 $(36.0 \%)$ and 21 to $25(35.5 \%)$ were most predominant. Six percent of the participants were between 36-40 years old. Most of the participants $(97 \%)$ were Christians, and were married 157 (78.5\%). Among the participants in the prospective study, 55
$(27.5 \%)$ had received primary level of education, $94(45.5 \%)$ secondary, and $54(27 \%)$ had received tertiary education.

The mean gestational age of the participants was 39.5 (SD 1.7) weeks and $5 \%$ of participants gave birth preterm.

The mean body mass index (BMI) of the participants was 28.8 (SD 5.0$) \mathrm{Kg} / \mathrm{m}^{2}$; range $18.1-47.6 \mathrm{Kg} / \mathrm{m}^{2}$. The majority of study participants were overweight $(58.5 \%)$. One $(0.5 \%)$ was underweight and $11(5.5 \%)$ had stage III obesity.

Sixty-one $(30.5 \%)$ participants were primigravidas, $36 \%$ primiparous, $30 \%$ multiparous, and $0.5 \%$ were grand multiparous. $18.5 \%$ of study participants had a history of abortion while $2.5 \%$ had a history of preterm births.

We observed that $8.5 \%$ of study participants were HIV positive, $17 \%$ had a perineal tear in a previous pregnancy and $6 \%$ had a previous episiotomy. Most of the study participants (55\%) did their ANCs at the secondary care centre (LRH) and the mean number of ANCs was 4.0 (SD 1.0) visits (range 1 to 8 visits). Ninety-nine percent of the babies were cephalic presentation. LOA position was most common $(65.2 \%)$ while ROP was marginal $(1.0 \%)$.

Fifteen percent of study participants underwent induction of labour and 20\% augmentation. There was no instrumental delivery or shoulder dystocia.

The mean duration of the second phase of labour was 37 (SD 18) minutes (range 15 to 120 minutes), and the mean birth weight 3241.3 (SD 501.4) g (range 1900g to 4900g). The mean Apgar score of the babies was 8.9 (SD 1.2) (range 0 to 10). Majority (52.3 $\%$ ) of the babies were male while $47.7 \%$ were female.

Figure 1: Most women in the LRH were delivered by nursing assistants compared with Obstetricians (56.5\% versus $2 \%$ ).

Out of 1336 participants in the retrospective study, $255(19.2 \%)$ had perineal tears while 31 (2.3\%) had medio-lateral episiotomies. Second-degree perineal tears were most prevalent 175 (13.1\%), followed by first-degree tears $77(5.8 \%)$. Three $(0.22 \%)$ of the tears were third-degree.

The mean age of participants with perineal tears and those without perineal tears was similar 25.9 (SD 5.4) versus 25.8 (SD 4.8).

Table 2: The incidence of perineal tears increased with maternal age $\mathrm{P}=0.002$. Participants who were $\geq 25$ years old were more likely to have perineal tears than those below 25 years old $\mathrm{P}=0.02$. Furthermore, participants with lower parity were more likely to have perineal tears $\mathrm{P}=0.02$ and women with previous perineal tear were also more likely to have a recurrence $\mathrm{P}=0.001$. The position of the fetal head especially occiputo-posterior, qualification of birth attendant (nursing assistant) were significantly associated with perineal tears $\mathrm{P}<0.001$, respectively.

Table 3: shows that the number of ANC visits less than 4 times $\mathrm{P}<0.007$ and prolonged second phase of labour (31-120 minutes) $\mathrm{P}<0.001$ were significantly associated with peritoneal tears.

The other factors studied: HIV status, Body mass index, previous 
Table 1. Socio-demographic characteristics.

\begin{tabular}{|c|c|c|}
\hline Variable & Frequency & Percentage \\
\hline \multicolumn{3}{|c|}{ Maternal Age (Years) } \\
\hline $16-20$ & 26 & 13 \\
\hline $21-25$ & 71 & 35.5 \\
\hline $26-30$ & 72 & 36 \\
\hline $31-35$ & 19 & 09.5 \\
\hline $36-40$ & 12 & 6 \\
\hline Total & 200 & 100 \\
\hline \multicolumn{3}{|l|}{ Education } \\
\hline Primary & 55 & 27.5 \\
\hline Secondary & 91 & 45.5 \\
\hline Tertiary & 54 & 27 \\
\hline Total & 200 & 100 \\
\hline \multicolumn{3}{|l|}{ Religion } \\
\hline Christian & 194 & 97 \\
\hline Muslim & 06 & 03 \\
\hline Total & 200 & 100 \\
\hline \multicolumn{3}{|c|}{ Marital Status } \\
\hline Married & 157 & 78.5 \\
\hline Single & 43 & 21.5 \\
\hline Total & 200 & 100 \\
\hline \multicolumn{3}{|c|}{$\begin{array}{c}\text { Gestational Age } \\
\text { (weeks) }\end{array}$} \\
\hline$<37$ & 10 & 05 \\
\hline $37-42$ & 139 & 69.5 \\
\hline$>42$ & 51 & 25.5 \\
\hline Total & 200 & 100 \\
\hline \multicolumn{3}{|l|}{ Gravidity } \\
\hline 1 & 61 & 5 \\
\hline 4-Feb & 126 & 69.5 \\
\hline$>4$ & 13 & 25.5 \\
\hline Total & 200 & 100 \\
\hline \multicolumn{3}{|l|}{ Parity } \\
\hline 1 & 72 & 36 \\
\hline 2 & 60 & 30 \\
\hline 4-Mar & 67 & 33.5 \\
\hline$\geq 5$ & 1 & 00.5 \\
\hline Total & 200 & 100 \\
\hline \multicolumn{3}{|c|}{$\begin{array}{c}\text { Body Mass Index } \\
(\mathrm{Kg} / \mathrm{m} 2)\end{array}$} \\
\hline$<18$ & 1 & 00.5 \\
\hline $18.5-24.9$ & 33 & 16.5 \\
\hline $25-29.9$ & 117 & 58.5 \\
\hline $30-34.9$ & 31 & 15.5 \\
\hline $35-39.9$ & 7 & 3.5 \\
\hline$\geq 40$ & 11 & 5.5 \\
\hline Total & 200 & 100 \\
\hline
\end{tabular}

episiotomy, birth weight, Apgar score $(<7)$ induction or augmentation of labour were not significantly associated with perineal tears.

Table 4: After logistic regression analysis maternal age was 2.6 times associated with perineal tears (aOR 2.6, 95\% CI: 1.1-4.3; $\mathrm{P}=0.02$. In the same light, participants with a history of previ- ous perineal tear were 3.4 times more likely to have a perineal tear (aOR 3.4, 95\% CI: 1.6=7.3; P=0.001). The position of the presenting part was 3.2 times associated with perineal tears (aOR 3.2, 95\% CI: 1.2-119; P<0.001). Furthermore, parturients with a prolonged duration of the second phase of labour were 3.2 times more likely to have perineal tears (aOR 3.2, 95\% CI: 1.71-6.04; $\mathrm{P}<0.001)$ and those who attended less than 4 ANC visits were 2.4 
Figure 1. Frequency distribution of study participants according to qualification of birth attendants $(\mathrm{N}=200)$.

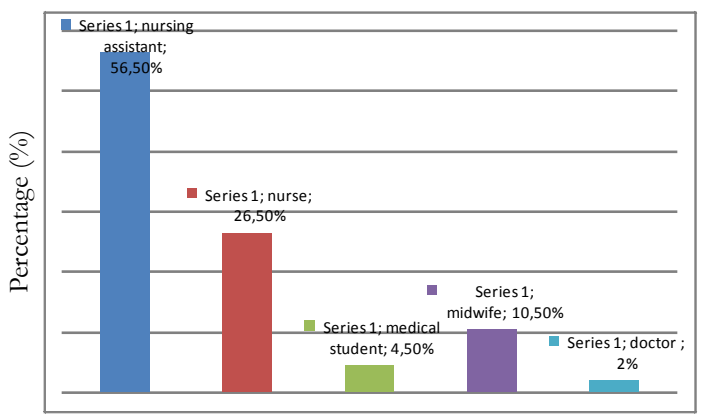

Qualification of birth attendant.

Table 2. Factors Associated with Perineal Tears in the Limbe Regional Hospital.

\begin{tabular}{|c|c|c|c|c|}
\hline Variable & $\begin{array}{c}\text { Presence of Perineal Tear (percentage) } \\
\text { N }(\%)\end{array}$ & $\begin{array}{c}\text { Absence of Perineal Tear (Percentage) } \mathrm{N} \\
(\%)\end{array}$ & $\begin{array}{l}\text { To- } \\
\text { tal }\end{array}$ & P-value \\
\hline \multicolumn{5}{|c|}{ Maternal Age (Years) } \\
\hline $16-20$ & $13(22.03 \%)$ & $13(9.22 \%)$ & 26 & 0.002 \\
\hline $21-25$ & $14(23.73 \%)$ & $57(40.43 \%)$ & 71 & \\
\hline $26-30$ & $26(44.07 \%)$ & $46(32.62 \%)$ & 72 & \\
\hline $31-35$ & $1(1.70 \%)$ & $18(12.77 \%)$ & 19 & \\
\hline Total & $59(100 \%)$ & $141(100 \%)$ & 200 & \\
\hline \multicolumn{5}{|c|}{ Parity } \\
\hline 1 & $30(50.85 \%)$ & $42(29.79 \%)$ & 72 & 0.02 \\
\hline 2 & $16(27.12 \%)$ & $44(31.21 \%)$ & 60 & \\
\hline 4-Mar & $13(22.03 \%)$ & $54(38.30 \%)$ & 67 & \\
\hline $18.5-24.9$ & $11(18.64 \%)$ & $22(15.60 \%)$ & 33 & \\
\hline $25-29.9$ & $31(52.54 \%)$ & $86(61.00 \%)$ & 117 & \\
\hline $30-34.9$ & $10(16.95 \%)$ & $21(14.89 \%)$ & 31 & \\
\hline $35-39.9$ & $3(05.09 \%)$ & $4(2.84 \%)$ & 7 & \\
\hline $40-50$ & $4(06.78 \%)$ & $7(4.96 \%)$ & 11 & \\
\hline Total & $59(100 \%)$ & $141(100 \%)$ & 200 & \\
\hline \multicolumn{5}{|c|}{$\begin{array}{c}\text { Previous Perineal Pathology } \\
\text { Perineal tear }\end{array}$} \\
\hline Yes & $18(30.51 \%)$ & $16(11.35 \%)$ & 34 & 0.001 \\
\hline LOA & $26(20.16 \%)$ & $103(79.84 \%)$ & 129 & $<0.001$ \\
\hline ROA & $3(75 \%)$ & $1(25 \%)$ & 4 & \\
\hline LOP & $28(44.44 \%)$ & $35(55.56 \%)$ & 63 & \\
\hline ROP & $1(50 \%)$ & $1(50 \%)$ & 2 & \\
\hline \multicolumn{5}{|c|}{ Qualification of birth attendant } \\
\hline Nursing assistant & $46(40.71 \%)$ & $67(59.29 \%)$ & 113 & $<0.001$ \\
\hline Nurse & $10(18.87 \%)$ & $43(81.13 \%)$ & 53 & \\
\hline Midwife & $0 \quad(0.00 \%)$ & $21 \quad(100.0 \%)$ & 21 & \\
\hline Med. Student & $03(33.3 \%)$ & $06(66.7 \%)$ & 09 & \\
\hline Doctor & $0 \quad(0.00 \%)$ & $04(100 \%)$ & 04 & \\
\hline \multicolumn{5}{|c|}{ Age Regrouped (years) } \\
\hline $16-24$ & $17(20.48 \%)$ & $66(79.52 \%)$ & 83 & 0.02 \\
\hline $25-40$ & $42(35.90 \%)$ & $75(64.10 \%)$ & 117 & \\
\hline
\end{tabular}

Statistical Analysis was with Chi Square and Fisher's Exact Test 
Table 3. Factors Associated with Perineal Tears (Labour Parameters) at the LRH.

\begin{tabular}{|c|c|c|c|c|}
\hline Variable & $\begin{array}{c}\text { Presence of Perineal } \\
\text { Tears N }(\%) \\
\end{array}$ & $\begin{array}{c}\text { Absence of Perineal } \\
\text { Tears N }(\%) \\
\end{array}$ & Total & P-value \\
\hline \multicolumn{5}{|c|}{ Induction of Labour } \\
\hline Yes & $11(18.64 \%)$ & $19(13.48 \%)$ & 30 & 0.4 \\
\hline No & $48(81.36 \%)$ & $122(86.52 \%)$ & 170 & \\
\hline Total & $59(100 \%)$ & $141(100 \%)$ & 200 & \\
\hline \multicolumn{5}{|c|}{ Augmentation of Labour } \\
\hline Yes & $15(25.42 \%)$ & $25(17.13 \%)$ & 30 & 0.2 \\
\hline No & $44(74.58 \%)$ & $116(82.27 \%)$ & 170 & \\
\hline Total & $59(100 \%)$ & $141(100 \%)$ & 200 & \\
\hline \multicolumn{5}{|c|}{ Duration of Second Phase of Labour (Minutes) } \\
\hline$<30$ & $24(40.68 \%)$ & $121(85.81 \%)$ & 145 & $<0.001$ \\
\hline $30-120$ & $35(59.82 \%)$ & $20(14.19 \%)$ & 55 & \\
\hline Total & $59(100 \%$ & $141(100 \%)$ & 200 & \\
\hline \multicolumn{5}{|c|}{ Apgar Score } \\
\hline$<7$ & $9(15.25 \%)$ & $10(7.09 \%)$ & 19 & $<0.07$ \\
\hline 10-Jul & $50(84.75 \%)$ & $131(92.91 \%)$ & 181 & \\
\hline Total & $59(100 \%)$ & $141(100 \%)$ & 200 & \\
\hline \multicolumn{5}{|c|}{ Birth weight $(\mathrm{g})$} \\
\hline$<3500$ & $39(66.10 \%)$ & $95(67.38 \%)$ & 134 & 1.0 \\
\hline $3500-4000$ & $20(33.90 \%)$ & $46(32.62 \%)$ & 66 & \\
\hline Total & $59(100 \%)$ & $141(100 \%)$ & 200 & \\
\hline Average Birth weights $\pm(\mathrm{SD}) \mathrm{g}$ & $3278 \pm 488.3$ & $3225.8 \pm 507.7$ & & 0.5 \\
\hline \multicolumn{5}{|c|}{ Human Immunodeficiency virus Status } \\
\hline Negative & $17(28.4 \%)$ & $124(87.94 \%)$ & 141 & 0.3 \\
\hline Positive & $42(41.2 \%)$ & $17(12.06 \%)$ & 59 & \\
\hline Total & $59(100 \%)$ & $141(100 \%)$ & 200 & \\
\hline \multicolumn{5}{|c|}{ Antenatal care visits } \\
\hline$>4$ times & $14(23.7 \%)$ & $127(90.07 \%)$ & 141 & $<0.007$ \\
\hline$<4$ times & $45(46.2 \%)$ & $14(9.93 \%)$ & 59 & \\
\hline Total & $59(100 \%)$ & $141(100 \%)$ & 200 & \\
\hline
\end{tabular}

Statistical analysis was with Chi Squared, Ficher's Exact Test and ANOVA

SD: Standard deviation.

Table 4. Risk Factors of Perineal Tears after Logistic Regression Analysis in the LRH.

\begin{tabular}{|c|c|c|c|c|}
\hline & \multirow{2}{*}{$\begin{array}{l}\text { Variable } \\
\text { P-value }\end{array}$} & \multirow{2}{*}{$\frac{\text { Bivariate }}{\text { P-value }}$} & \multicolumn{2}{|c|}{ Multivariate } \\
\hline & & & aOR & $95 \% \mathrm{CI}$ \\
\hline \multicolumn{5}{|c|}{ Maternal Age } \\
\hline & 0.02 & 0.02 & 2.6 & $1.1-4.3$ \\
\hline \multicolumn{5}{|c|}{ Parity } \\
\hline $\begin{array}{c}1 \\
2 \\
3-4 \\
5-9\end{array}$ & 0.02 & $\begin{array}{c}\text { Constant } \\
0.015 \\
0.002 \\
\text { undefined }\end{array}$ & $\begin{array}{c}\text { Constant } \\
0.2 \\
0.3 \\
\text { undefined }\end{array}$ & $\begin{array}{c}\text { Constant } \\
0.1-0.8 \\
0.05-0.05 \\
\text { Undefined }\end{array}$ \\
\hline History of Perineal Tear & 0.001 & 0.002 & 3.4 & $1.6-7.3$ \\
\hline History of Episiotomy & 0.34 & 0.35 & 1.8 & $0.57-0.60$ \\
\hline \multicolumn{5}{|c|}{ Position of Presenting Part } \\
\hline $\begin{array}{c}\text { LOA } \\
\text { LOP } \\
\text { ROA } \\
\text { ROP } \\
\text { Duration of second phase of labour } \\
\text { Number of ANC visits } \\
\text { BMI }\end{array}$ & $\begin{array}{c}<0.001 \\
0.007 \\
0.8\end{array}$ & $\begin{array}{c}\text { Constant } \\
<0.001 \\
0.04 \\
0.34 \\
<0.001 \\
0.008 \\
0.36\end{array}$ & $\begin{array}{c}\text { Constant } \\
3.2 \\
11.9 \\
4.0 \\
3.2 \\
2.4 \\
1.4\end{array}$ & $\begin{array}{l}\text { Constant } \\
1.64-6.12 \\
1.2-119.0 \\
0.24-65.5 \\
1.71-6.04 \\
1.26-4.53 \\
0.69-2.74\end{array}$ \\
\hline \multicolumn{5}{|c|}{ Qualification of birth attendant } \\
\hline Nursing assistant Nurse & $<0.001$ & Constant & Constant & Constant \\
\hline Midwife & & Undefined & Undefined & Undefined \\
\hline Medical Student & & Undefined & Undefined & Undefined \\
\hline Medical Doctor & & 0.55 & 0.6 & $0.10-3.46$ \\
\hline
\end{tabular}

CI: Confidence Interval; aOR: Adjusted Odds Ratio; LOA: Left occiputo-anterior; LOP: Left occiputo-posterior; ROA: Right occiputo-anterior; ROP: Right occiputo-posterior; ANC: Antenatal care. 
times more likely to have perineal tears (aOR 2.4, 95\% CI: $1.26-$ 4.53; $\mathrm{P}=0.007)$.

Body Mass Index, qualification of birth attendant and parity were independently not associated with perineal tears.

\section{Discussion}

Our study, set in the Limbe Regional Hospital, a secondary care center in a semi-urban town in Cameroon, aimed at determining the prevalence and risk factors of perineal tear in order to provide baseline data that may assist in auditing obstetric practice.

The prevalence of perineal tear in this study was found to be $19.2 \%$ and that of episiotomy to be $2.3 \%$. Second-degree perineal tears were the most prevalent $(13.1 \%)$ while third-degree tears were the least prevalent $(0.22 \%)$. The results also confirmed that factors such as maternal age, history of previous perineal tear, number of ANC visits $(<4)$, position of presenting part (occiputo-posterior) and duration of second phase of labour ( $>30 \mathrm{~min}-$ utes) independently, had a statistically significant effect on perineal tear. Also, babies delivered to women with perineal tear were not likely to suffer from poor Apgar scores.

\section{Socio-demographic characteristics}

The average age of the study participants was 25.8 (SD 5.0) in the prospective study and 26.2 (SD 5.3) in the retrospective study. Most of the study participants were among the age group 26 to 30 in the retrospective and 21 to 25 in the prospective phases of the study. These figures were slightly higher than the average maternal age of 24.9 (SD 5.9) reported by Christianson et al., in 2003 [10], and slightly lower than those obtained by Lesley et al in 2013. They latter placed the mean maternal age of nulliparous women at 29.1 and that of multiparous women at 31.7 [11]. The results in our study can be explained by the high sexual activity of women in their twenties. The higher mean ages in the study by Lesley et al., can be explained by the fact that the UK is a highincome economy where most women are more career oriented and so turn to childbearing much later in life than the women in our setting.

Most of the study participants were married and Christians, and had attained secondary education. The findings from this study revealed that parturients suffered from perineal tear irrespective of their religion, marital status, educational level, geographical location or ethnicity.

\section{Prevalence of perineal tear}

Out of 1336 participants enrolled in the retrospective study, $255(19.2 \%)$ had perineal tear. This figure is higher than the $13.5 \%$ (230/1695) obtained in Yaoundé [5] and also higher than the prevalence obtained in Port Harcourt Nigeria; $10 \%$ for first degree tears and lower than the $25 \%$ obtained for second degree perineal tears out of 4720 vaginal births [12].

The prevalence of episiotomy was $2.3 \%$ and this was lower than the $15 \%(60 / 400)$ reported for first and second confinement at the University of Port Harcourt in Nigeria in 2008 [13] and 22\% (91/410) deliveries in Nepal in 2009 [14].
Current evidence supports restrictive use of episiotomy [15] and explains the high prevalence of perineal tears in the LRH; a fact compounded further by the poor qualification of birth attendants in the LRH. $56.5 \%$ of births were by nursing assistants and only $2 \%$ by obstetricians. Little wonder, given the current doctorpatient ratio of 1:12000 in Cameroon $[15,16]$. The obstetricianpatient ratio is even higher.

Furthermore, perineal and pelvic floor morbidity is usually greatest among women receiving episiotomy as compared to those remaining intact or sustaining spontaneous perineal tears [2]. Episiotomy is causally related to third-and fourth-degree tears [2].

\section{Types of perineal tear}

Second-degree perineal tear was more prevalent $(13.1 \%)$, followed by first-degree tear $(5.8 \%)$. Third-degree tear occurred in only $0.22 \%$ of the cases. We did not record any $4^{\text {th }}$-degree tears in our series, but our $3^{\text {rd }}$-degree tears were lower than the study in Yaounde that reported 1.3\% third degree tears [5]. The overall prevalence of first, second and third-degree tears was lower than that obtained in a study carried out in 2009 in Tansen Mission Hospital in Nepal, and which reported a prevalence of $55.4 \%$, $43.2 \%$ and $1.4 \%$ for first, second and third-degree perineal tears, respectively [14]. The prevalence of third degree tears in this study $0.22 \%$ was lower than that obtained in 2011 in South Africa $0.6 \%$ of 31665 deliveries suffering a third and fourth degree perineal tear [1]. The study by Leonard and Gerhard in Tygerberg Hospital, South Africa, was a retrospective case control study where birth registers were used to identify only cases of third and fourth degree perineal tears following vaginal births compared with parturients who had normal vaginal births [1]. The rate of third degree perineal tears in our study was lower than that obtained in a study carried out in San Francisco, California in 2003 (4.4\%) [10] and also lower than that obtained in North Devon District Hospital in 2009(1.6\%) [1,17]. These studies all had larger sample sizes than our study: Hirayama F., Koyanagi A., Mori R. et al., 2012 did a multi-country study to investigate the prevalence and risk factors of third- and fourth-degree perineal lacerations in developing countries (seven African countries, nine Asian and eight Latin American countries. Altogether, 373 facilities were studied between 2004 and 2008 and 214599 parturients who underwent vaginal delivery were analysed to investigate the risk of third and fourth degree perineal tears). Out of the 373 facilities included in our study, 142 reported no cases of third- and fourth-degree tears. Suspected under-reporting was highly prevalent in countries such as China and Uganda, where 90.5 and $75.0 \%$ of the facilities, respectively, did not report any cases of third- and fourth-degree tears. On the other hand, suspected over-reporting was common in the Philippines, where three out of 17 facilities reported more than $60 \%$ of women having third- or fourth-degree tears. The overall prevalence in the study was $0.6 \%$ (range $0.1-1.4 \%$ ) when facilities with suspected under- and over-reporting were excluded [1]. Groutz A., Cohen A., Gold G. et al., 2011 analyzed obstetric database of 31784 consecutive parturients who gave birth from January 2007 to December 2009 was screened for cases of thirddegree or fourth-degree perineal tears. Four controls, matched by time of delivery, were selected for each case of third-or fourthdegree perineal tear. Maternal and obstetric parameters were analyzed and compared between the study and control groups [19]. Finally, the low rates of third-degree perineal tears in our study 
may result from under-reporting [1].

\section{Predisposing factors of perineal tear}

In our study a number of known predisposing factors of perineal tear were found to be statistically significant. These included maternal age (25-40), nulliparity, history of previous perineal tear, occiputo-posterior position of presenting part, duration of second phase of labour (>30 minutes), and factors indicating quality of care (less than four ANC visits and most importantly qualification of birth attendant). These factors are similar to those obtained by Nkwabong et al., in 2013, who found risk factors like nulliparity, maternal age (27 and above), birth weight $(>3500 \mathrm{~g})$, and instrumental and adolescent deliveries [5]; and Leonard and Gerhard in 2011 who found occiputo-posterior position, assisted deliveries, shoulder dystocia, and nulliparity to be contributory factors to perineal tear [1]. Risk factors for third and fourth-degree perineal tears obtained by Eskandar and Shet in the UK included occiputo-posterior positions, high birth weight and primigravidas [19]; and risk factors obtained by Groutz et al., [17] included Asian ethnicity, nulliparity, vacuum delivery, persistent occiputo-posterior positions, and heavy birth weight [18]. It should be noted that in the above studies, information about the parity of the women was collected before they gave birth.

Nulliparity as a predisposing factor of perineal tear can be explained by the reduced elasticity of the pelvic floor in parturients who had never given birth. In participants with birth records, the elasticity is higher. However, studies have shown that antenatal digital perineal massage by the parturient or her partner for about one month starting from the $35^{\text {th }}$ week of pregnancyis associated with reduced perineal trauma; there is a statistically significant $16 \%$ reduction in the incidence of episiotomies in women who practice perineal massage [20]. Furthermore, amongst women with a previous vaginal birth, perineal massage reduces the likelihood of postpartum perineal pain and perineal pain at three months $[20,21]$. This modality is more common among nulliparous women and is widely accepted by women [20]. Women in the LRH should therefore be oriented towards this practice. Malposition is associated with perineal trauma; the presenting diameter in the occiputo-posterior position was larger than the occiputo-anterior position and the fetus had to do 135 degrees of internal rotation in occiputo-posterior as against 45 degrees in the occiputo-anterior position, thereby increasing the risks of perineal tear $[18,19]$. There was also a statistically significant relationship between second-stage of labour $(>30)$ minutes and the occurrence of perineal tear. This was similar to the result obtained by Lesley et al. in 2013 [11]. A previous perineal tear will always result in a scarred perineum that will more easily get torn than an unscarred perineum. This was confirmed by the results in our study and in studies by Payne et al., (1999), Edwards et al. (2006), and Lowder et al. (2007) [22-24]. Furthermore, the training of obstetricians and midwives has been shown to be more thorough as regards labour and delivery than that of nurses and nursing assistants. The former are more skilled in obstetric practice than the latter and therefore usually face fewer problems in delivery situations. It was therefore not surprising that perineal tears were higher in deliveries by nursing assistants than in those by midwives and obstetricians. An interesting finding was the relationship between the number of ANCs and perineal tears. ANC is a key, population-wide public health intervention to prevent adverse pregnancy outcomes [26]. The World Health Organization
(WHO) recommends that all women have at least four antenatal care assessments by or under the supervision of a skilled attendant [26]. Under-attending of ANC results in low birth weight babies, preterm births, obstetric complications, and neonatal mortality [25]. Attending ANC normally will aid in the monitoring of the pregnancy for early identification of risk factors and appropriate intervention. However, nulliparity and qualification of birth attendant were independently not associated with perineal tears in this study.

Other factors mentioned in the literature but not found to be statistically significant in our study include BMI, GA, HIV status, previous episiotomy, breech presentation, induction and augmentation of labour and high birth weights. In cases of HIV positive participants, more care was always taken to avoid perineal tears and episiotomies to prevent mother-to-child transmission of the virus.

The association between factors like shoulder dystocia, instrumental deliveries, and perineal oedema could not be established because these factors were not assessed in our study. Of importance here was the birth weight. The mean birth weight of babies born to participants with perineal tears was roughly similar to the mean birth weight of those without perineal tears (3278.5 (SD 488.3) g and 3225.8 (SD 507.7) g, respectively). There were very few women who had babies with frank macrosomia, probably because they would have been identified earlier in labour due to poor progress of labourand CPD and delivered by CS. Previous episiotomy was not found to be associated with tears in this study probably due to the low rates of episiotomy in this hospital.

Apgar score, for its part, is an important score for measuring newborn survival. It is affected by factors such as precipitate delivery, nuchal cord, preterm delivery, placenta previa, abruptio placenta, and meconium aspiration [27-29]. In this study, the mean Apgar scores of those with tears were similar to those without tears. The relationship between perineal tears and poor Apgar scores was not statistically significant. Therefore, neonatal outcome was not affected by the presence or absence of tears. The presence or absence of a perineal tear was therefore not a predictor of Apgar scores. Leonard and Gerhard (2011) reached a similar conclusion [30]. Their study was a case control study, and they found an average Apgar score of 9.3 in the study group and 9.4 in the control group. The similarities between the average Apgar scores led to the conclusion that neonatal outcome did not differ between the two groups [30].

\section{Study Limitations}

Part of the study was retrospective. There was insufficient information in some files, and others were incorrectly filled. The study was hospital-based; therefore only women who gave birth at the LRH participated in it.

Finally, the study was carried out in only one health facility in the Limbe Health District. The results obtained cannot therefore be generalised to the whole health district.

\section{Conclusion}

The prevalence of perineal tears in the LRH was $19.2 \%$. Sec- 
ond-degree perineal tears were the most common type of tears observed. Factors independently associated with perineal tears in the LRH hospital included maternal age $(\geq 25)$ years, a history of previous perineal tears, ANC visits $(<4)$, position of the presenting part (occiputo-posterior), duration of second stage of labour (>30minutes). Paturients at the LRH should be monitored carefully for these factors so that appropriate and timely interventions can be effected when necessary. Perineal outcomes at the LRH were excellent and should be maintained or improved.

\section{Recommendations}

Similar studies should be carried out in other centres in Cameroon. This could help in the development of a scoring system to determine the factors associated with perineal tears and preventive measures developed. Archiving and handling of birth registers at the LRH should be improved.

\section{Authors Contribution}

TOE contributed in the project conception, analysis and interpretation of data, and writing of the manuscript. He is the corresponding author. WAT and RT contributed in data analysis and interpretation, and proof read the manuscript. KLN and ENE contributed in designing the research, data collection, analysis and interpretation and drafting of the article. REM proofread the manuscript.

\section{Acknowledgements}

We would like to thank the administrative authorities and maternity staff of the Limbe Regional Hospital for making this study possible by allowing us to consult their birth registers/medical records. We are also thankful to the patients who consented and made the prospective study possible, and to the medical students who helped in data collection.

\section{References}

[1]. Hirayama F, Koyanagi A, Mori R, Zhang J, Souza J, et al., (2012) Prevalence and risk factors for third- and fourth-degree perineal lacerations during vaginal delivery: a multi-country study. BJOG Int J Obstet Gynaecol 119:340-347.

[2]. Klein MC, Gauthier RJ, Robbins JM, Kaczorowski J, Jorgensen SH, et al (1994) Relationship of episiotomy to perineal trauma and morbidity, sexual dysfunction, and pelvic floor relaxation. Am J Obstet Gynecol 1994 171:591-598.

[3]. Klein MC, Kaczorowski J, Robbins JM, Gauthier RJ, Jorgensen SH, et al (1995) Physicians' beliefs and behaviour during a randomized controlled trial of episiotomy: consequences for women in their care. CMAJ Can Med Assoc J 153(6):769-779.

[4]. Klein MC, Janssen PA, MacWilliam L, Kaczorowski J, Johnson B (1997) Determinants of vaginal-perineal integrity and pelvic floor functioning in childbirth. Am J Obstet Gynecol 176(2):403-410.

[5]. Nkwabong E, Kouam L, Orock GT, Ekono MR, Takang W, et al., (2013) Study of Perineal Tears During Delivery of Singletons in Cephalic Presentation. Trop J Obstet Gynaecol 26:128-131.

[6]. Sachs JD (2012) From millennium development goals to sustainable development goals. The Lancet 379:2206-2211.
[7]. Loewe M (2012) Post 2015: How to Reconcile the Millennium Development Goals (MDGs) and the Sustainable Development Goals (SDGs)?. German Development Institute.

[8]. Hartmann K, Viswanathan M, Palmieri R, Gartlehner G, Thorp J, et al., (2005) Outcomes of routine episiotomy: a systematic review. JAMA 293(17):2141-2148

[9]. Fouelifack FY, Tameh TY, Mbong EN, Nana PN, Fouedjio JH, et al., (2014) Outcome of deliveries among adolescent girls at the Yaoundé central hospital. BMC Pregnancy Childbirth 14:102.

[10]. Christianson LM, Bovbjerg VE, McDavitt EC, Hullfish KL (2003) Risk factors for perineal injury during delivery. Am J Obstet Gynecol 189(1):255260.

[11]. Smith LA, Price N, Simonite V, Burns EE (2013) Incidence of and risk factors for perineal trauma: a prospective observational study. BMC Pregnancy Childbirth 13:59.

[12]. Enyindah CE, Fiebai PO, Anya SE, Okpani AO (2007) Episiotomy and perineal trauma prevalence and obstetric risk factors in Port Harcourt, Nigeria. Niger J Med J Natl Assoc Resid Dr Niger 16(3):242-245.

[13]. Nyengidiki TK, Nyeche S (2013) Post -Episiotomy Morbidity amongst Parturients at the University of Port Harcourt Teaching Hospital, Port Harcourt, Nigeria. Niger Health J 8:16-19.

[14]. Joshi A, Acharya R (2009) Perineal Outcome after Restrictive use of Episiotomy in Primi-gravida. J Nepal Med Assoc 48(176):269-8.

[15]. Scott RE, Ndumbe P, Wootton R (2005) An e-health needs assessment of medical residents in Cameroon. J Telemed Telecare 11(suppl 2):78-80.

[16]. Fongwa MN (2002) International Health Care Perspectives: The Cameroon Example. J Transcult Nurs 13:325-330.

[17]. Groutz A, Cohen A, Gold R, Hasson J, Wengier A (2011) Risk factors for severe perineal injury during childbirth: a case-control study of 60 consecutive cases. Colorectal Dis 13:e216-e219.

[18]. Groutz A, Hasson J, Wengier A, Gold R, Skornick-Rapaport A (2011) Third- and fourth-degree perineal tears: prevalence and risk factors in the third millennium. Am J Obstet Gynecol 204:347.e1-4.

[19]. Eskandar O, Shet D (2009) Risk factors for $3^{\text {rd }}$ and $4^{\text {th }}$ degree perineal tear. J Obstet Gynaecol J Inst Obstet Gynaecol 29:119-122.

[20]. Beckmann MM, Stock OM (2013) Antenatal perineal massage for reducing perineal trauma. Cochrane Database Syst Rev 4.

[21]. Beckmann MM, Garrett AJ (2006) Antenatal perineal massage for reducing perineal trauma. Cochrane Review 25(1): CD005123.

[22]. Payne TN, Carey JC, Rayburn WF (1999) Prior third- or fourth-degree perineal tears and recurrence risks. Int J Gynaecol Obstet 64:55-57.

[23]. Edwards H, Grotegut C, Harmanli OH, Rapkin D, Dandolu V (2006) Is severe perineal damage increased in women with prior anal sphincter injury? J Matern-Fetal Neonatal Med 19(11):723-727.

[24]. Lowder JL, Burrows LJ, Krohn MA, Weber AM (2007) Risk factors for primary and subsequent anal sphincter lacerations: a comparison of cohorts by parity and prior mode of delivery. Am J Obstet Gynecol 196(4):344.e1-5.

[25]. Heaman MI, Newburn-Cook CV, Green CG, Elliott LJ, Helewa ME (2008) Inadequate prenatal care and its association with adverse pregnancy outcomes: a comparison of indices. BMC Pregnancy Childbirth 8:15.

[26]. Villar J, Bergsjo P (2002) WHO antenatal care randomized trial: Manual for the implementation of the new model. Geneva.

[27]. Rh P, Ks K, Ah M (1979) Obstetric factors influencing outcome in infants weighing from 1,001 to 1,500 grams. Am J Obstet Gynecol 133(5):503508.

[28]. Wax JR, Pinette MG, Cartin A, Blackstone J (2010) Maternal and newborn morbidity by birth facility among selected United States 2006 low-risk births. Am J Obstet Gynecol 202(2):152.e1-5.

[29]. Li X, Wan J, Xu C, Zhang Y, Fang L, et al., (2004) Misoprostol in labour induction of term pregnancy: a meta-analysis. Chin Med J (Engl) 117(3):449452.

[30]. Juul L, Theron GB (2011) Risk factors for third- and fourth-degree perineal tears during vaginal delivery. Urogynaecologia 25:e2. 